\title{
(SIDA)DANIA E SAÚDE DE TRAVESTIS E TRANSEXUAIS

\author{
CITIZENSHIP (THROUGH STD/AIDS) \\ AND HEALTH OF TRANSVESTITES \\ AND TRANSSEXUALS
}

\author{
Juliana Vieira Sampaio \\ julianavsampaio@hotmail.com \\ Doutoranda em Psicologia pela Universidade Federal de Pernambuco. \\ Camila Aleixo de Campos Avarca \\ camilaavarca@hotmail.com \\ Mestre em Psicologia Social pela Pontifícia Universidade Católica de São Paulo.
}

\section{RESUMO}

Transexuais e travestis são apontadas como um dos grupos que mais sofrem com o preconceito por subverterem a heterossexualidade compulsória, como também os padrões de masculinidade e feminilidade vigentes. Entre as violências enfrentadas estão a falta de acesso aos serviços de saúde e atendimentos inadequados decorrentes do preconceito dos profissionais que atuam no Sistema Único de Saúde, apesar da saúde integral, equânime e com garantia de acesso a todos os níveis de atenção ser um direito garantido a todos os cidadãos em Constituição Federal desde 1990. Outras políticas transversais, como a Política Nacional de Humanização de 2003 e a Política Nacional de Saúde Integral de Lésbicas, Gays, Bissexuais, Travestis e Transexuais de 2010, apesar de terem por objetivo qualificar o atendimento em saúde - e, no segundo caso, especificamente à população LGBT - ainda há disparidade no atendimento para determinados grupos que se encontram em situação de desigualdade. Diante de tantas controvérsias, o objetivo deste artigo é discutir o acesso da população de travestis e transexuais aos serviços públicos de saúde na de cidade Fortaleza, Ceará. O aporte teórico-metodológico da Teoria Ator-Rede (TAR) foi utilizado de modo a compreender a rede de actantes (humanos e não-humanos) em interação que produzem, como um dos efeitos, a limitação no acesso à saúde pelas pessoas trans. Concluímos que uma das controvérsias centrais envolvidas no atendimento de travestis e transexuais é a limitação das suas necessidades ao campo da DST/Aids, como um processo de repatologização das sexualidades dissidentes.

Palavras-chave: Saúde. Travestis. Transexuais.

\begin{abstract}
Transsexuals and transvestites are seen as one of the groups most affected by prejudice by subverting compulsory heterosexuality, but also the prevailing masculinity and femininity standards. The violence suffered because the lack of access to health system and inadequate care resulting from the prejudice of professionals working in the National Health System called SUS, despite the integral health, equal and guaranteed access to all levels of care is a right guaranteed every citizen in the Constitution since 1990 Others policies known such cross-cutting, as the National Humanization Policy (2003) and the National Policy on Integral Health of Lesbian, Gay, Bisexual, Transvestites
\end{abstract}


and Transsexuals (2010), although they had intended to improve health care - and in the latter case, specifically directed to LGBT population - there are still disparities in care for certain groups who are in unequal situation. With so many controversies, the purpose of this article is to discuss the access of the population of transvestites and transsexuals in public health services in the city of Fortaleza, Ceará. The theoretical and methodological support of Actor-Network Theory (ANT) was used to understand the actants' networking (human and nonhuman) in interaction that produces, as one of the effects, limited access to health system for trans people. We conclude that one of the central controversies involved in health care for transvestites and transsexuals is the limitation of their needs to the field of sexually transmitted diseases (STD) - AIDS, as a re-pathologization process to dissident sexualities.

Keyword: Health. Transvestites. Transsexuals.

\section{INTRODUÇÃO}

O presente trabalho é o recorte de uma pesquisa mais ampla da dissertação de mestrado sobre o acesso da população de travestis e transexuais aos serviços públicos de saúde na de cidade Fortaleza, Ceará. Transexuais e travestis são apontadas (BRASIL, 2010a) como um dos grupos que mais sofrem com o preconceito por subverterem a heterossexualidade compulsória, como também os padrões de masculinidade e feminilidade vigentes. Nessa direção, estudos apontam que o preconceito dos profissionais da saúde tem prejudicado o atendimento adequado dessa população (GONZÁLEZ, LINCONA, 2006; ROMANO, 2007; CAMPO-ARIAS, HERAZO, 2008, CAMPO-ARIAS, HERAZO, COGOLLO, 2010; CERQUEIRA-SANTOS, CALVETTI, ROCHA, MOURA, BARBOSA, HERMEL, 2010). Buscamos por meio desta pesquisa exploratória discutir as controvérsias, a partir da Teoria ator-rede (LATOUR, 2012), que estão envolvidas no atendimento da população trans dentro dos equipamentos de saúde.

A saúde é um direito recente da população brasileira que só foi garantido na Constituição Federal de 1988, como resultado da luta de diversos grupos sociais. Até então, o sistema público de saúde atendia apenas aqueles que contribuíam para a Previdência Social, os que não tinham direitos, nem dinheiro, dependiam da caridade e filantropia. Com a criação do Sistema Único de Saúde (SUS), oficializado pelo Congresso Nacional através da aprovação da Lei Orgânica da Saúde em 1990, a saúde passou a ser acessível para todos os brasileiros sem discriminação (BRASIL, 2006). O objetivo do SUS é oferecer "a assistência às pessoas por intermédio de ações de promoção, proteção e recuperação da saúde, com a realização integrada das ações assistenciais e das atividades preventivas" (BRASIL, 1990, art. $5^{\text {a)}) . ~}$

Para alcançar o seu objetivo, o SUS é orientado por algumas diretrizes e princípios que norteiam as ações e os serviços de saúde em território nacional. Três são os princípios doutrinários do SUS: Universalidade, Equidade e Integralidade. A universalidade garante atenção à saúde a qualquer cidadão; a equidade assegura que todos sejam atendidos de forma igual, sem privilégios ou preconceitos, mas respeitando as diferenças e necessidades de cada um de acordo com a complexidade do caso; por último, o princípio da integralidade é o reconhecimento de que a atenção em saúde deve abranger ações de promoção, prevenção, tratamento e reabilitação, com acesso a todos os níveis de complexidade do SUS (BRASIL, 2009).

Mesmo orientado por tais diretrizes, alguns estudos (LIONÇO, 2008; MELLO, PERILO, BRAZ, PEDROSA, 2011) apontam que ainda existe disparidade no atendimento em saúde para determinados grupos que se encontram 
em situação de vulnerabilidade e desigualdade e, por isso, tornou-se necessário construir novas políticas públicas (BRASIL, 2010a, 2010b, 2011a) para assegurar tal direito. Lionço (2008) aponta que a dificuldade do acesso dessas populações à atenção em saúde é atravessada, principalmente, pelo preconceito sofrido nos serviços do que por necessidades específicas e intrínsecas desses sujeitos. Os atendimentos procurados pela população LGBT não se diferenciam da demanda cotidiana dos serviços de saúde, em qualquer nível de atenção. Do mesmo modo, não há patologias que exigem um acompanhamento diferenciado na rede. Precisam, apenas, de acolhimento respeitoso e resolutivo, levando em conta a singularidades das pessoas, conforme preconiza o Ministério da Saúde a partir da Política Nacional de Humanização, o chamado "HumanizaSUS".

A Política Nacional de Humanização (BRASIL, 2003), atuando de forma transversal em todas as ações e políticas no SUS, e, considerada como um elemento de gestão que tem por objetivo pôr em prática os princípios do SUS no cotidiano dos serviços traz o acolhimento como uma de suas principais diretrizes (BRASIL, 2010; 2013). De acordo com Ministério da Saúde (BRASIL, 2013) acolhimento é "reconhecer o que o outro traz como legítima e singular necessidade de saúde" (p. 7) e tem o "compromisso com o reconhecimento do outro, na atitude de acolhê-lo em suas diferenças, suas dores, suas alegrias, seus modos de viver, sentir e estar na vida" (BRASIL, 2010, p. 6).

No caso da política de saúde construída pelo governo brasileiro em associação com o movimento LGBT, a "Política nacional de saúde integral de lésbicas, gays, bissexuais, travestis e transexuais" (BRASIL, 2010a) tem como proposta assegurar o direito à saúde até então cerceado aos sujeitos que resistem de algum modo ao padrão heterossexual. O combate ao preconceito e à discriminação são temáticas constantes nesse documento, podendo ser observadas nos objetivos e nas diretrizes desse material. Um exemplo da centralidade do combate ao preconceito nesse texto pode ser visualizado no objetivo geral dessa Política (BRASIL, 2010a, p. 16), que propõe:

“[...] promover a saúde integral de lésbicas, gays, bissexuais, travestis e transexuais, eliminando a discriminação e o preconceito institucional, contribuindo para a redução das desigualdades e para a consolidação do SUS como sistema universal, integral e equânime."

Porém, alguns autores (MELLO, PERILO, BRAZ, PEDROSA, 2011) têm observado que, mesmo com a implantação de políticas públicas, essas populações historicamente excluídas não têm acessado os serviços públicos de saúde.

\section{PERSPECTIVAS TEÓRICO- METODOLÓGICAS}

As controvérsias são fontes privilegiadas de análise e, por isso, cabe questionar este hiato entre as políticas que buscam assegurar saúde integral à população LGBT e o cotidiano marcado pela falta de acesso aos serviços de saúde e práticas excludentes dos profissionais que atuam na rede.

Dois posicionamentos teórico-metodológicos podem ajudar nesta compreensão: o primeiro insere a "política pública" dentro do campo discursivo: termo polissêmico constituído socialmente e caracterizado por seu processo histórico. Segundo Celina Souza (2006, p. 26):

"Pode-se, então, resumir política pública como o campo do conhecimento que busca, ao mesmo tempo, 'colocar o governo em ação' e/ou 
analisar essa ação (variável independente) e, quando necessário, propor mudanças no rumo ou curso dessas ações (variável dependente). A formulação de políticas públicas constitui-se no estágio em que os governos democráticos traduzem seus propósitos e plataformas eleitorais em programas e ações que produzirão resultados ou mudanças no mundo real".

Para Peter Spink (2009) o uso generalizado do termo política pública sugere um conjunto de decisões racionais tomadas com seriedade por organismos hierárquicos cujo fim é o avanço no bem-estar comum, respeitando os princípios democráticos. Mas, o que acontece na prática é uma luta entre as ações públicas e as pessoas, visando assegurar que os recursos e as atenções se centrem onde o governo considerar ser importante, não necessariamente imbicadas com as necessidades da população. Quanto mais desigual esta luta, mais permeada por conflitos e contradições estarão as práticas cotidianas do setor público.

Em resposta a essa construção conceitual atemporal, acrítica e a-histórica sobre política, o autor propõe uma observação processual e cuidadosa, procurando questionar o que os governos elegem fazer ou não fazer. Por que alguns temas atraem o governo e outros não? Que temas tem acesso à agenda principal e por quê? Ao aprofundar essas perguntas, far-se-á possível e necessário compreender todo o terreno social e de organização onde as decisões são tomadas, seus recursos e suas ações e não somente o conteúdo da política em si. Ressalta o autor que "estas preguntas nos llevará a posar una mirada más atenta a esas agrupaciones de personas relativamente estables, agrupaciones, redes y organizaciones que, sea de su agrado o no, se encuentran constantemente ligadas a temas similares"(SPINK, 2009, p. 18).

Redes e agrupações: esse é o foco da segunda perspectiva teóricometodológica a ser utilizada neste artigo. A Teoria Ator-Rede (TAR) vem se consolidando como um método na construção do saber científico desde a década de 80, a partir das publicações de Bruno Latour e Michel Callon.

O termo Teoria Ator-Rede, embora utilizado, é questionado pelos próprios autores, a saber: 1). Por que não se trata de uma teoria e sim de um método, um caminho para seguir a construção de fatos. 2). Há também a dificuldade com o termo rede, pois não deve ser algo pensado como algo estático e, também, não há uma só entrada na rede. Além de ser heterogênea, composta por humanos e não-humanos e 3). E há, também, o problema com a palavra ator, que se confunde com ator das ciências sociais. Um ator não precisa ser humano, necessariamente. Ator é tudo que tem agência e se define pelos efeitos de suas ações, incluindo materialidades (LATOUR, 2009). Nesse sentido, compreenderse-á as políticas públicas - além de construídas socialmente e atravessadas por processo histórico - como produtos de actantes (humanos e não-humanos) em interação (SILVA, 2011).

Para Latour, a proposta é aceitação de híbridos, bem como a dos humanos e não humanos na produção de conhecimento, pensando a ciência sem aprisionamentos como objetividade, neutralidade e racionalidade. (MORAES, 2004). Na teoria ator-rede - proposta para uma ciência não aprisionada, nem moderna - a noção de rede refere-se a fluxos, circulações, alianças, movimentos: não pode ser entendida como uma entidade fixa.

A partir desses referenciais metodológicos, buscam-se, neste artigo, as associações a partir de um trabalho minucioso de seguir os próprios atores, alimentando-se de contradições, incertezas e mapeando controvérsias das ações. Para isso, é preciso compreender que 1) toda ação muda o estado das coisas. Se não mudar, não é ação. 2) os atores têm suas próprias explicações sobre os 
efeitos das ações (lembrando que os objetos também possuem agência) e 3) por isso é preciso repetir a descrição do mundo social tal como ele é, sem a tradução acadêmica ou seja, "registrar e não filtrar. Descrever e não disciplinar" (LATOUR, 2012, p. 88).

\section{SAÚDE INTEGRAL OU CIDADANIA?}

Assim que identificado o interesse pela discussão da saúde da população de travestis e transexuais, decidiu-se explorar esta rede heterogênea em ação a partir de buscas por eventos técnico-científicos nesta área, na cidade de Fortaleza. O primeiro deles foi o seminário "Saúde Mental, homofobia, lesbofobia e transfobia institucional”, cuja divulgação feita por e-mail ressaltava a importância do mesmo:

"O objetivo do Seminário é debater a problemática da saúde mental relacionada à população de Lésbicas, Gays, Bissexuais, Travestis e Transexuais (LGBT). Segundo a Coordenação Municipal DST/Aids e Hepatites Virais da Secretaria Municipal de Saúde de Fortaleza (SMS), a ideia é reconhecer que esse público adoece com depressão e outros transtornos mentais, devido à discriminação e ao preconceito.”

Em um primeiro momento, essa informação não pareceu relevante, apesar de parecer atípico o responsável pelo evento que debateria saúde mental ser a coordenação do Programa DST/Aids e não da Coordenação de Saúde Mental do município: uma controvérsia.

Chegando ao evento, em frente à mesa de inscrição havia um espaço com muitas pessoas, algumas usando perucas, acessórios e preservativos espalhados pelo chão que funcionavam como cenário para os participantes do Seminário que desejassem tirar uma foto para ser postada no site do evento e receber um kit com preservativo, lubrificante e um folheto explicativo. Esses kits foram elementos constantes durante todo o processo da pesquisa: o que será que esses materiais estavam querendo comunicar? Essa é uma das pistas fornecida pela metodologia da Teoria ator-rede (TAR) (LATOUR, 2009): é preciso atenção não só para os actantes humanos, mas também para os não humanos, pois eles também produzem efeitos. Ou, em outras palavras, eles performam realidades.

Com isso, observamos, também, a presença insistente de cartazes sobre prevenção, diagnóstico e tratamento de DST/Aids em diversos eventos que tinham a proposta de discutir qualquer temática voltada para o público LGBT, como o Seminário sobre "Política da assistência social no combate a homofobia, lesbofobia, transfobia institucional", que aconteceu também na cidade de Fortaleza.

Esses actantes não humanos, kits e cartazes, também dialogavam com integrantes das mesas dos eventos, pois em todos os Seminários havia a presença de um representante da coordenadoria de DST/Aids de Fortaleza. Essa repetição da temática DST/Aids, primeiramente, provocou estranhamento, mas depois passou a fazer sentido quando conectada à história do movimento LGBT no Brasil (GAMSON, 2006; SIMÕES, FACCHINI, 2009).

A organização do movimento de lésbicas, gays, bissexuais e transgêneros no Brasil tem uma história recente que se inicia no final da década de 1970, influenciada pelas lutas feministas e étnicas (GAMSON, 2006). Esse movimento passa a ganhar maior visibilidade na década de 80 , com o surto epidêmico da Aids e é durante esse período que se constrói uma parceria entre o movimento LGBT e o governo brasileiro, a fim de combater a doença, cul- 
minando, em 1988, na formulação do "Programa Nacional de doenças Sexualmente Transmissíveis (DST) e AIDS" pelo Ministério da Saúde.

Os gays foram classificados, em um primeiro momento do surto da Aids, como um "grupo de risco", assim como se deu com os profissionais do sexo e usuários de drogas. Isso provocou uma discriminação e estigmatização dessas populações, mas, apesar disso, se produziu em torno da Aids uma série de ações voltadas para as pessoas afetadas pelo vírus, como também para possíveis vítimas, entre elas, os gays. Foram essas atividades que favoreceram o fortalecimento do movimento homossexual no Brasil. Muitas associações e grupos gays foram fundados nesse período a partir do financiamento de programas governamentais e da associação com instituições internacionais que combatiam a Aids. (SIMÕES; FACCHINI, 2009).

\begin{abstract}
"A meu ver, o vírus da Aids realizou em alguns anos uma proeza que nem o mais bem-intencionado movimento pelos direitos homossexuais teria conseguido, em muitas décadas: deixar evidente à sociedade que homossexual existe e não é outro, no sentido de um continente à parte, mas está muito próximo de qualquer cidadão comum, talvez ao meu lado e - isto é importante! - dentro de cada um de nós, pelo menos enquanto virtualidade." (TREVISAN, 2000 apud SIMÕES, FACCHINI, 2009, p. 135).
\end{abstract}

A luta contra a epidemia possibilitou que a homossexualidade ganhasse visibilidade, favorecendo o debate em diversos espaços da sociedade. A Aids produziu uma série de efeitos sobre o movimento gay, que passou a ser nomeado, na década de 1990, de GLBT e depois LGBT, reunindo não apenas homens homossexuais, mas uma diversidade de pessoas que não se encaixavam na norma heterossexual. O crescimento do movimento LGBT e o "sucesso" no combate à Aids possibilitou que se formasse uma "aliança" com o governo brasileiro.

Esse espaço de negociação política permitiu que emergissem novas demandas e a proposição de projetos de lei nos níveis federal, estadual e municipal, agora não mais atrelados apenas à área da saúde e ao combate à Aids, mas que se ampliaram para os campos da educação, cultura, trabalho, direitos humanos e outros (MISKOLCI, 2011). Dessa forma, podemos perceber que, nos últimos dez anos, foram elaboradas diversas políticas públicas (BRASIL, 2004, 2009b, 2010a) no Brasil, voltadas, especificamente, para a população LGBT. Apesar das políticas terem se expandido para áreas diferentes da saúde e da DST/Aids, podemos perceber o quanto essas temáticas ainda permanecem fortemente associadas às necessidades da população LGBT quando observamos os cenários dos Seminários que participamos e dos equipamentos de saúde que visitamos posteriormente.

Todos os espaços visitados que tinham como proposta discutir questões relacionadas às pessoas LGBT, de algum modo também estavam atravessados pela temática da DST/Aids. Decidiu-se, então, continuar nessa trajetória, seguindo esse rasto. O próximo ponto da rede seria a Coordenadoria de DST/ Aids de Fortaleza (CDA).

\title{
PRIMEIRA PARADA: OS ESPECIALISTAS
}

A CDA fica localizada no terceiro andar de um prédio antigo no centro da cidade, junto com outras instituições que formam a Secretaria de Saúde da cidade de Fortaleza. Logo na porta existe um cartaz informando sobre o uso do preservativo; ao lado, pregado na parede, há um flanelógrafo grande com 
cartazes falando sobre a testagem rápida de HIV, prevenção de sífilis e outras DSTs. Entrando na sala da Coordenadoria, percebeu-se que o espaço é bastante pequeno para a quantidade de material presente. Logo na entrada, foi avistada uma caixa grande cheia de preservativos (trata-se de uma estratégia de facilitar o acesso ao preservativo e, assim como essa, existem mais 74 espalhadas em pontos estratégicos da cidade), duas mesas onde ficavam computadores antigos, nas paredes mais cartazes sobre DST/Aids, só que agora aparecem alguns voltados, especificamente, para a população LGBT. Diversos materiais foram disponibilizados durante a visita: panfletos e cartazes de campanhas produzidos tanto pelo Ministério da Saúde como pela própria CDA, em parceria com a prefeitura de Fortaleza.

Foram realizadas duas visitas à Coordenadoria de DST/Aids de Fortaleza, em dois meses subsequentes, uma antes das eleições municipais e outra após a mudança na gestão da cidade. Com isso, muitos projetos que estavam sendo desenvolvidos foram interrompidos e outros que estavam em construção foram arquivados à espera de um momento mais propício: um deles era justamente o trabalho voltado para o atendimento de travestis em uma região de saúde do município. Nesses dois encontros na CDA foi possível conversar com dois profissionais diferentes, responsáveis por ações distintas na instituição o que possibilitou amplitude na compreensão das ações desenvolvidas pela Coordenadoria e como ela se articula nas ações voltadas para travestis e transexuais na cidade.

Grande parte do trabalho desenvolvido na CDA é realizada em parceria com outros pontos da rede de atenção à saúde. Destacam-se o Consultório de Rua, (a partir de ações orientadas pela perspectiva da redução de danos) e por meio de Organizações não Governamentais (ONGs) espíritas, ONGs LGBT, ONGs que combatem a exploração sexual, Associação de Trabalhadores do Sexo, escolas, hospitais etc.

Muitas são as ações da Coordenadoria de DST/Aids voltadas, especificamente, para a população LGBT, como promoção de campanhas e palestras, participações em eventos, tal qual a Parada pela Diversidade Sexual de Fortaleza. Todas essas atividades estão articuladas para combater o aumento da prevalência de DST/Aids entre a população LGBT, que historicamente tem sido a maior vítima dessas doenças, sendo 11 vezes maior a taxa de incidência de Aids nesse grupo se comparado com a população em geral (BRASIL, 2007). Porém, Pelúcio e Miskolci (2009) alertam que o modelo padrão de prevenção da Aids tem visibilizado aqueles que são reconhecidos socialmente como possuidores de uma sexualidade desviante, prostitutas, michês, travestis, gays, transexuais, mas acabam obscurecendo os outros que participam dessa relação, como os clientes dos profissionais do sexo e os homens que mantêm relações sexuais com travestis, transexuais e gays, mas se identificam e são identificados no cotidiano como heterossexuais.

Travestis e transexuais passam a ter assistência à saúde quando são reconhecidos pelo Estado como sujeitos "sujos" que precisam ter a sua sexualidade higienizada a partir de um padrão heterossexual. A saúde das trans passa a ser resumida ao campo da DST/Aids. Não foi raro, após informar que pesquisávamos saúde de travestis e transexuais, surgir a pergunta "mas é DST/Aids?", inclusive as próprias trans faziam esse tipo de questionamento (SANTOS, 2002; MONTOYA, BECERRA, 2010; VUJOSEVICH, GIMÉNEZ, GODOY, MOREIRA, 2003).

Esse fenômeno de visibilidade política e social das trans pela via da Aids é chamado por Pelúcio (2007) de SIDAdanização (Aids, Síndrome da Imunodeficiência Adquirida, em espanhol, é SIDA). Sai o "c" e entra o "s", 
uma cidadania alcançada pela repatologização da sexualidade não heterossexual. Entretanto, para que as travestis e transexuais adquiram a SIDAdania, precisam partilhar os pressupostos do programa de prevenção de DST/Aids, compreendendo a responsabilidade que têm sobre si e os cuidados que devem dedicar à saúde, a partir do modelo biomédico.

Dentro desta perspectiva, outras atividades promovidas regularmente pela Coordenadoria de DST/Aids são os treinamentos junto aos profissionais da saúde sobre o atendimento de pacientes infectados pelo vírus HIV, pois muitos se negam a atender essa população. Os profissionais da CDA informam que, nessas capacitações, sempre é inserida a temática da diversidade sexual relacionando ao campo dos direitos humanos. Em outros momentos, as palestras são direcionadas, especificamente, para debater esse tema, como no "III Encontro saúde sem lesbofobia, homofobia e transfobia, 2012". Essas palestras de treinamento e formação têm como público alvo desde os Agentes Comunitários de Saúde (ACS), profissionais de nível superior dos postos aos professores das escolas públicas de Fortaleza, já que as ações da CDA se propõem a ser intersetoriais, atuando em escolar, postos, centros comunitários, terreiros de umbanda etc.

A maioria das questões relacionadas à sexualidade, desde as campanhas para incentivar o uso de preservativo até as discussões sobre homofobia nos serviços de saúde, fica sob a responsabilidade da equipe da Coordenadoria de DST/Aids. Esses profissionais ficam marcados como um dos poucos capacitados para falar sobre essa temática, como também tratar das populações marcadas pela sexualidade. Devido a essa particularidade, a equipe do CDA tem produzido oficinas, treinamentos, palestras e capacitações entre os profissionais de diversos setores da saúde para que eles sejam agentes multiplicadores. Como a equipe do CDA é pequena, eles não têm como capacitar todos os profissionais da rede de saúde. Dessa forma, iniciaram o processo de capacitação com algumas pessoas que, dentro dos equipamentos, já são identificadas como referência no trabalho com sexualidade por realizarem oficinas, promoverem discussões sobre o tema nos serviços onde atuam, estando, assim, mais abertas ao diálogo. Mesmo com esse cuidado, eles relatam que não é incomum alguns funcionários convidados saírem da sala durante a palestra por se recusarem a ouvir sobre a temática da diversidade sexual, quando não fazem cara feia ou qualquer sinal de indignação ou nojo.

Para atingir especificamente a população de travestis e transexuais, a Coordenadoria tem desenvolvido ações para mapear as áreas onde elas se concentram, geralmente zonas de prostituição em bairros periféricos de Fortaleza. Depois do mapeamento, há uma orientação para que algumas trans que trabalham nesses locais sejam capacitadas a fim de que elas realizem a atividade de busca ativa, distribuindo preservativos e fazendo o diálogo entre as trans e um posto de saúde de referência. Ocorre, também, distribuição de panfletos e cartazes com campanhas sobre prevenção e tratamento de DST/Aids nesses espaços. Outras ações da CDA destinadas às pessoas trans, apesar de não serem, especificamente, o público alvo, foram atividades intersetoriais, produzidas junto aos povos de santo, nos terreiros de religiões de matrizes africanas.

As religiões de matriz africana, de modo geral, não estigmatizam as pessoas trans, não sendo incomum que pais e mães de santo sejam travestis e transexuais e, com isso, a circulação desses sujeitos nesses espaços seja respeitada. (SOUZA, MALVASI, SIGNORELLI, PEREIRA, 2013).

Sempre que perguntávamos aos profissionais da saúde, integrantes do movimento LGBT, funcionários das coordenadorias de Fortaleza sobre lugares que são referência no atendimento de travestis e transexuais, indicavam os mes- 
mos lugares: duas unidades básicas de saúde que são modelos como centro de testagem rápida de $\mathrm{HIV}$, um hospital especializado no tratamento de pacientes soropositivos e um Centro de Especialidades Médicas, que também oferece Serviços de Atenção Especializada em HIV.

\section{SEGUNDA PARADA: EQUIPAMENTOS DE SAÚDE PARA QUEM?}

Tendo em vista que o foco da pesquisa não era trabalhar com o tema DST/Aids entre travestis e transexuais, apesar da insistência do campo-tema em apontar essa temática. Optou-se por visitar uma das unidades básicas de saúde (UBS) indicadas como referência no atendimento das trans, tendo em vista a perspectiva da saúde integral desta população.

A Atenção Básica- AB é considerada a ordenadora do cuidado da rede de saúde, uma vez que é no território que o cuidado nas UBS se estabelecem e a partir da proximidade e o vínculo com os usuários que se dá o seu cotidiano de ações.A Estratégia Saúde da Família - ESF, formalizada em 1994, tem como princípios de atuação a integralidade, qualidade, equidade e participação social, em que as intervenções predominantes se realizam por equipes interdisciplinares que se corresponsabilizam pela promoção e prevenção de saúde, na cura e recuperação, com predomínio das ações planejadas e programadas em dados epidemiológicos e priorizados para famílias ou grupos com maior vulnerabilidade social, índice que pode ser agravante no processo de adoecimento (equidade), com o estimulo à participação comunitária.

A UBS foi escolhida como local de visita por ser instituída como a porta de entrada do SUS e os pacientes não precisarem ter nenhuma demanda pré-estabelecida para serem atendidos, diferente do ambulatório e hospital especializado no tratamento de Aids. As unidades básicas de saúde são responsáveis por realizar atendimentos de atenção básica à população de determinado território, de forma programada ou não, nas especialidades básicas, oferecendo assistência de profissionais de nível superior (BRASIL, 2009). A USB visitada fica no centro da cidade de Fortaleza, território apontado por alguns interlocutores como lugar de moradia de muitas travestis e transexuais.

A visita à UBS foi realizada em uma quarta-feira pela manhã. $\mathrm{Na}$ recepção aos usuários, poucos cartazes pregados em um quadro de aviso. Entre eles, um panfleto informando os horários de testagem rápida de HIV e sífilis (terça e quinta das $15 \mathrm{~h}-17 \mathrm{~h}$ e quarta de $18 \mathrm{~h}-20 \mathrm{~h}$ ). Porém, os cartazes e panfletos sobre prevenção, diagnóstico e tratamento de DST/Aids produzidos, especificamente, para população LGBT, apesar de frequentes nas ONGs, Coordenadorias de DST/Aids e LGBT ou no Centro de Referência LGBT, sumiram do equipamento de saúde, ficando apenas aqueles "assexuados" ou que remetiam à heterossexualidade. A ausência marcou sua presença.

Cartazes de campanha como os encontrados na Coordenadoria de DST/Aids não são usualmente expostos nos postos de saúde. Segundo o profissional da Coordenadoria de DST/Aids, é porque eles são produzidos em menor quantidade e preferencialmente distribuídos em áreas onde há maior circulação da população LGBT, como ONGs. Por outro lado, os integrantes das ONGs dizem que não encontram esse material fixado em outros espaços, pois costuma escandalizar e algumas pessoas podem achá-lo ofensivo. Se existe uma demarcação prévia dos locais onde serão expostos tais cartazes, de acordo com o trânsito das pessoas LGBTs, isto sinaliza que elas não estão presentes 
em todos os espaços do serviço de saúde. Há uma exclusão dessa população nas UBS, desde o momento em que se pressupõe a sua ausência nesses lugares.

Entrando um pouco mais nas dependências do posto, encontramos a farmácia, onde dois funcionários trabalham entregando medicamentos e preservativos, à frente ficam os guichês destinados à entrega de senhas para atendimento. No corredor à direita, um grupo formado por mulheres com crianças pequenas está esperando atendimento, consulta ou vacina. Em seguida, outro cartaz informando sobre os horários dos testes de HIV e sífilis. Na porta das salas existem papeis sinalizando que tipo de atendimento é realizado ali: coordenadoria, teste de HIV e sífilis, ginecologia e obstetrícia, vacinação etc. O final do corredor acaba em um pátio onde estão os banheiros e salas restritas apenas aos funcionários.

Na tentativa de dialogar com os funcionários da UBS, um lugar oportuno pareceu ser a Farmácia: local movimentado onde ocorre a dispensação de medicamentos. Foi questionado à atendente se travestis e transexuais costumam ir naquele posto. Inicialmente, ela parece não entender a questão, depois de um tempo, diz que sim, alguns já foram atendidos lá, tem uns três que às vezes aparecem para buscar preservativos, mas que não é algo muito comum. Perguntouse o que geralmente elas buscam quando vão à farmácia. Diz ela que varia: "o último veio pegar amoxicilina, pois ia fazer um implante dental". A atendente orienta que, para obter mais informação, é melhor conversar com a enfermeira que realiza o acolhimento dos pacientes e com uma das agentes comunitária de saúde (ACS) que sempre conversa com "os travestis".

Seguindo os caminhos que foram sendo trazidos pelo atores da rede,o próximo rumo foi a sala de atendimento para conversar com a enfermeira indicada. Após aguardar alguns pacientes serem atendidos, iniciou-se a conversa com a enfermeira e logo foi informada sobre o objetivo da pesquisa. A enfermeira comenta que há apena um mês está naquela unidade de saúde, é a responsável pelo acolhimento dos pacientes, encaminhando-os para os médicos que estão disponíveis e também é treinada para realizar o teste rápido de HIV. De acordo com ela, foram "atendidos" três travestis e apenas "os" reconheceu por estarem "vestidos" de mulher.

Nesse momento, a enfermeira se dirige para um médico que também está na sala e pergunta se alguma vez ele atendeu "algum travesti". O médico fica pensativo e diz que acha que consultou apenas dois, em três anos de trabalho nessa UBS, apesar de acreditar que foram mais, já que "a maioria deles vem descaracterizado para o posto". Ele explica que "alguns vêm para o posto e dão o nome de José, mas de noite devem ser Rebeca". Duas funcionárias, provavelmente enfermeiras ou técnicas de enfermagem, que também estão nessa mesma sala, entram na conversa:

“[...] uma vez a gente atendeu 'um travesti' que precisou tomar uma injeção de benzetacil no braço, porque 'ele' tinha silicone no bumbum e na coxa. Tivemos medo de furar alguma coisa. Acho que 'ele' tinha sífilis em um estado bem grave, pois a pele estava bem comprometida.”.

Após cada um relatar a sua experiência de atendimento com alguma travesti, eles orientam a ida a outra UBS, pois nessa atendiam poucos casos já que não eram referência em teste de HIV. Mesmo existindo esse serviço, "é raro as pessoas procurarem teste de HIV aqui, às vezes eles acabam se estragando por falta de procura. Só na época da campanha nacional do Ministério da Saúde 'Fique Sabendo' é que surge demanda". Os profissionais passam a me indicar UBS que são referência na testagem de HIV e/ou que estão na periferia da cidade 
e em zonas de prostituição. Também informam que a assistente social do posto poderia ajudar, mas teria que retornar outro dia, pois aquele não era o turno dela.

Para esses profissionais não fazia sentido realizar a pesquisa naquele posto, pois a maior parte dos pacientes é formada por mulheres e crianças, um ambiente "de família". Portanto, não apareceriam travestis e transexuais com tanta frequência, apesar do centro da cidade ser um lugar conhecido pela circulação e prostituição de travestis. É importante salientar que um dos principais acessos ao sistema de saúde, na Atenção Básica, é a Estratégia de Saúde da Família (ESF), que está associada à constituição de família pelo padrão heterossexual (LIONÇO, 2008). Travestis e transexuais são vistos justamente como o oposto de família, são aqueles que foram expulsos dos seus lares e que, mesmo construindo novos laços, não são reconhecidos e legitimados como família (BUTLER, 2003). O momento político atual, inclusive, parece corroborar com essa noção: recentemente foi aprovado na comissão especial da Casa o PL 6.583/2013, chamado de "Estatuto da Família" cuja definição de família se caracteriza pela união entre homem e mulher.

Na semana seguinte, retornou-se à UBS para conversar com a assistente social, que está em uma sala reservada para os funcionários junto com duas agentes comunitárias de saúde e duas psicólogas. É explicado para as pessoas presentes o foco da pesquisa e a indicação feita por outros profissionais da UBS para realizar a conversa com a assistência social sobre o acompanhamento das trans no posto. A assistente social convida para sentar e parece bastante interessada em ajudar: apresenta-se informando que está no posto há apenas quatro meses, mas que trabalhou durante muitos anos na Coordenadoria de DST/Aids. Quando a profissional se identificou como uma outrora participante da equipe da CDA, a sua fala passou a fazer sentido, pois até o momento era estranho o fato de a assistente social fazer referência às travestis e transexuais usando o gênero feminino e não apresentar qualquer desconforto ao conversar sobre o assunto, postura muito diferente dos outros profissionais até o momento.

Uma das ACS também participa da conversa, afirmando que os profissionais sempre estranham quando aparece alguma trans na UBS e que a chamam para ajudar no atendimento, pois ela, diferente dos outros ACS, gosta de trabalhar com esse público, distribuindo preservativos e lubrificantes, apesar de, no seu território de atuação, não ter nenhuma.

"O registro dos pacientes no sistema do posto é pelo nome da identida-
de, deixando as travestis constrangidas. Quando vejo, coloco o nome
social do lado e aviso para o médico que na ficha tem um nome de
homem, mas que vai entrar uma mulher. Acho falta de respeito, a pes-
soa toda vestida de mulher e ficarem chamando por nome de homem.".

Mesmo assim, a ACS diz ser rara a presença de trans, na UBS, que conversa mais com as meninas quando as encontra na rua. Elas sempre lhe pedem preservativo, pois no posto, muitas vezes, é solicitada a identidade, além de alguns profissionais quererem restringir a quantidade de preservativo a ser entregue para as trans, que geralmente precisam de várias por causa do trabalho na prostituição. "Muitas preferem ir aos bancos de preservativo que ao posto de saúde, pois lá não questionam a quantidade". A outra ACS presente na sala fica o tempo todo calada, parece um pouco desconfortável com a conversa e logo sai.

A assistente social informa que, durante esse período de trabalho na UBS, não acompanhou o atendimento de nenhuma travesti ou transexual: "o problema começa desde a recepção, quando não se respeitam o uso do nome social, muitos acham que o tratamento de saúde já é suficiente". A psicóloga fala que só acompanhou uma trans, a qual foi fazer o teste rápido de HIV, 
que inclusive deu positivo, mas depois disso não viu mais nenhuma. A outra psicóloga informa que só viu dois na sala de espera para atendimento médico, complementa, afirmando que já trabalhou em seis postos de saúde anteriormente e nesse tempo nunca viu travesti.

As visitas exploratórias aos serviços de saúde indicados como referência no atendimento de travestis e transexuais na cidade de Fortaleza nos ajudou a perceber como a norma sexual heteronormativa e baseada no binarismo de sexo/ gênero organiza as ações do serviço público de saúde. Além disso, observamos com a pesquisa como acontece um processo de re-patologização das sexualidades não heterossexuais, na medida em que os equipamentos voltados para DST/ Aids tornam-se os principais espaços institucionalizados para a saúde trans.

\section{CONSIDERAÇÕES FINAIS}

Há um distanciamento das travestis e transexuais dos serviços de saúde e de uma tentativa de atenção integral que é produzido, entre outras questões, pela adoção por parte do Estado de uma noção heteronormativa e binária de sexo e gênero como base de suas ações e que finda por excluir os corpos que escapam e subvertem a norma sexual. Em contrapartida, tal lógica normalizadora também pode nos ajudar a pensar novas possibilidades de existência, Butler (2010) sustenta que é necessário se opor ao regime normativo dentro dele já que não existe um espaço fora do poder, mas este pode ser subvertido e deslocado:

\footnotetext{
"É preciso transformar o campo das instituições sociais em um vasto campo experimental, de forma a determinar quais são os pauzinhos a mexer, quais são os parafusos a afrouxar aqui ou ali para introduzir a mudança desejada; é preciso efetivamente desencadear uma operação de descentralização, por exemplo, para aproximar os usuários dos centros de decisão dos quais eles dependem e implica-los nos processos decisórios, evitando com isso essa espécie de integração globalizante que deixa as pessoas em uma completa ignorância de tudo o que condiciona tal ou tal interrupção." (FOUCAULT, 2010, p. 132).
}

O Estado tem capturado, pela via da DST/Aids, travestis e transexuais, como também, as tem excluído dos outros campos do cuidado em saúde. Entretanto, não podemos reduzir as estratégias de governo na saúde a um problema simples de gestão do Estado, uma vez que a saúde atravessa "todos os lugares e relações cotidianas" (MENEGON, 2010, p. 224). A saúde não depende, simplesmente, do direito e de políticas públicas. Travestis e transexuais produzem saúde e doença a partir das suas relações cotidianas, negociando não só com os equipamentos oficiais do Estado, mas também construindo de modo singular uma forma própria de compreender o que é saúde. Não é o direito à saúde que vai impedir que o sujeito adoeça, como também não é o saber biomédico que sempre irá definir e classificar o que são práticas produtoras de saúde e de doença.

As ações do Estado têm o seu limite, pois as necessidades da população são heterogêneas e não podem ser atendidas como um todo, seja por questões financeiras, seja por dificuldades estratégicas. Com diz Foucault (2010, p. 138), seria impossível "satisfazer todas as carências de saúde na linha interminável em que ela se desenvolve". Daí, "o problema levantado é, portanto, o de relacionar uma demanda infinita com um sistema finito" (p. 140). Mesmo compreendendo as limitações da política e do direito, é importante entendermos como são eleitas as prioridades do sistema de saúde e quais são as forças envolvidas na sua regulação. Apesar da finitude da produção de saúde pelo Estado, esta deve ser 
sempre flexível e provisória, não pode ser estabelecida "de uma vez por todas por uma definição médica da saúde nem pela noção de 'necessidade de saúde' enunciada como um absoluto" (p. 137).

\section{REFERÊNCIAS}

BENEDETTI, Marcos. Toda Feita: o corpo e o gênero das travestis. Rio de Janeiro. Garamond Universitária, 2005.

BRASIL. Ministério da Saúde. Lei Federal no 8.080, de 19 de setembro de 1990. Brasília, DF, 1990.

. Política Nacional de Humanização. Brasília: Ministério da Saúde, 2003.

. Conselho Nacional de Combate à Discriminação. Brasil Sem Homo-

fobia: Programa de combate à violência e à discriminação contra GLTB e promoção da cidadania homossexual. Brasília: Ministério da Saúde, 2004.

. Ministério da Saúde. A construção do SUS: história da Reforma Sanitária e do Processo Participativo. Brasília: Ministério da Saúde, 2006.

. Plano nacional de enfrentamento da epidemia de Aids e das DST entre gays, HSH e travestis. Brasília: Ministério da Saúde, 2007.

. O SUS de A a Z: garantindo saúde no municípios. Ministério da Saúde, Conselho Nacional das Secretarias Municipais de Saúde. 3. ed. Brasília: Editora do Ministério da Saúde, 2009.

. Acolhimento nas práticas de produção de saúde. Ministério da Saúde, 2a edição 5a reimpressão Série B. Textos Básicos de Saúde Brasília, $2^{\circ}$ ed. Brasília: Editora do Ministério da Saúde, 2010.

. Política Nacional de Saúde Integral de Lésbicas, Gays, Bissexuais, Travestis e Transexuais. Brasília: Ministério da Saúde, 2010 a.

. Política Nacional de Saúde Integral da população negra: uma política do SUS.Brasília: Ministério da Saúde, 2010b. Saúde, 2011

Portaria ${ }^{\circ} 122$, de 25 de janeiro de 2011. Brasília: Ministério da

. Relatório sobre violência homofóbica no Brasil: ano de 2011. Brasí-

lia, DF: Secretaria de Direitos Humanos, 2012.

. Nota técnica conjunta de 2012. Brasília, Ministério da Saúde, 2012 a.

. Política Nacional de Humanização, PNH: material de apoio. Brasília: Ministério da Saúde, 2013.

CAMPO-ARIAS, Adalberto; HERAZO, Edwin. Homofobia en estudiantes de medicina: uma revisiónde los diez últimos años. MedUNAB, 11, p. 120-123, 2008.

; HERAZO, Edwin; COGOLLO, Zuleima. Hommofhobia among nursing students. Rev. Esc. Enferm. USP, v. 44, n. 3, 2010.

CARRARA, Sergio; VIANNA, Adriana. "Tá lá o corpo estendido no chão...": a Violência Letal contra Travestis no Município do Rio de Janeiro. Physis: Revista de Saúde Coletiva. Rio de Janeiro, v. 16, n. 2, p. 233-249, 2006.

CERQUEIRA-SANTOS, Elder; CALVETTI, Prisla; ROCHA, Katia; MOURA, Andreína; BARBOSA, Lúcia; HERMEL, Júlia. Percepção de usuários gays, lésbicas, bissexuais e transgêneros, transexuais e travestis do sistema único de saúde. Revista Interamericana de Psicologia, v. 4, n. 2, p. 235-245, 2010.

FOUCUALT, Michel. Ditos e Escritos V: Ética, Sexualidade, Política. 2. ed. Rio de Janeiro: Forense Universitária, 2010. 
GAMSON, Joshua. As sexualidades, a teoria queer e a pesquisa qualitativa. In: DENZIN, N. K.; LINCOLN, Y.S. O planejamento da pesquisa qualitativa: teorias e abordagens. Porto Alegre: Artmed/Bookman, 2006. p. 345-362. GONZÁLEZ, María; LINCONA, Nelso. Normalízacion del discurso homofóbico. Aspecto bioético. Acta Bioethica, v.12, n.2, 2006.

LATOUR, Bruno. Jamais Fomos modernos: ensaio de antropologia simétrica. 2 ed. Rio de Janeiro: Editora 34, 2009.

. Reagregando o social: uma introdução à teoria do ator-rede. Salvador: Edufba, 2012.

LIONÇO, Tatiana. Que direito à saúde para a população GLBT? Considerando direitos humanos, sexuais e reprodutivos em busca da integralidade e da equidade. Revista Saúde Sociedade, São Paulo, v. 17, n. 2, p. 11-21, 2008.

MELLO, Luiz; PERILO, Marcelo; BRAZ, Camilo; PEDROSA, Claudio. Políticas de saúde para lésbicas, gay, bissexuais, travestis e transexuais no Brasil: em busca de universalidade, integralidade e equidade.Sexualidad, Salud y Sociedad-Revista Latinoamericana, n. 9, p. 7-28, 2011.

MENEGON, Vera. Tecnologias em saúde reprodutiva: implicações nos modos de ser contemporâneos. In: JOBIM, Solange; MORAIS, Márcia (Org). Tecnologias e modos de ser no contemporâneo. Rio de Janeiro: Ed. PUC-Rio: 7 letras, 2010.

MISKOLCI, Richard. Teoria Queer e a sociologia: o desafio de uma analítica da normalização. Revista Sociologias, Porto Alegre - RS, ano 11, n. 21, jan/ jun, p. 150-182, 2009.

. Não ao sexo rei: da estética da existência foucaultiana à política queer. In: SOUSA, L.; SABATINE, T; MAGALHÃES, B. (Orgs.). Michel Foucault: sexualidade, corpo e direito. Marília. Oficina Universitária, São Paulo: Cultura Acadêmica, 2011.

MONTOYA, John; BECERRA, Andrea. Reconficuraciones de género e vunerabilidad al VIH/SIDA em mujeres trangénero en Colombia. Revista Gerencia y Políticas de Salud, vol 9, № 18 Bogotá, jan-jun, 2010.

MORAES, Márcia. A ciência como rede de atores: ressonâncias filosóficas. Hist. cienc. saude-Manguinhos, Rio de Janeiro, v. 11, n. 2, Aug. 2004.

PELÚCIO, Larissa. Nos nervos, na carne, na pele: uma etnografia travesti sobre o modelo preventivo de aids. 2007. Tese (Doutorado em Ciências Sociais) - Programa de Pós-graduação em Ciências Sociais, Universidade Federal de São Carlos, São Carlos, 2007.

PELÚCIO, Larissa; MISKOLCI, Richard. A prevenção do desvio: o dispositivo da aids e a repatologização das sexualidades dissidentes. Sexualidad, Salud y Sociedad: Revista Latinoamericana. Vol. 1, p. 125-157. Rio de Janeiro: CLAM-IMS-UERJ, 2009.

ROMANO, Valéria. Inclusão não homofóbica: um diálogo entre estudantes de medicina e travestis. Revista Brasileira de Med. Fam. e Com., Rio de Janeiro, v. 3, n. 10, jul-set, 2007.

SANTOS, Ana. Sexualidades Politizadas: ativismos nas áreas da AIDS e da orientação sexual em Portugal. Caderno de Saúde Pública, Rio de Janeiro, 18 (3): 595-611, mai-jun, 2002.

72 SANTOS, Boaventura de Sousa. A Gramática do tempo: para uma nova cultura política. São Paulo, Cortez, 2006.

SIMÕES, Júlio; FACCHINI, Regina. Na trilha do arco-íris: do movimento homossexual ao LGBT. São Paulo: Editora Fundação Perseu Abramo, 2009.

SILVA, Fernanda Calderaro. Política de saúde voltadas às lésbicas: um estudo sobre a possibilidade de reverter um quadro histórico de invisibilidade. (Mestrado em Psicologia Social). Programa de Estudos Pós Graduados 
em Psicologia Social. Pontifícia Universidade Católica de São Paulo, São Paulo, 2011.

SILVA, Fernando; TONELI, Juraci; BECKER, Simone. Ele é feita para apanhar/ela é bom de cuspir / Maldito Geni: especulações sobre a condição de abjetos vivida por travestis. Revista Científica eletrônica de psicologia, $\mathrm{n}$. $10,2010$.

SOUZA, Celina. Políticas públicas: uma revisão da literatura. Sociologias, Porto Alegre, ano 8, n. 16, p. 20-45, jul/dez 2006.

SOUZA, Marta; MALVASI, Paulo; SIGNORELLI, Marcos; PEREIRA, Pedro. Itinerário Terapêutico de travestis da região central do Rio Grande do Sul. Ciência e Saúde Coletiva, v. 18, p. 1085, 2013.

SPINK, Peter. Los psicólogos y las polícas públicas en América Latina: El big mac y los caballos de Troia. Psicoperspectivas, VIII (2), 12-34, 2009.

VOLCOV, Katerina; VASCONCELLOS, Maria da Penha. Crack, é possível vencer" ou é preciso compreender: observações a partir de campanhas publicitárias do governo. Sau. \& Transf. Soc., Florianópolis, v. 4, n. 2, p. 99-105, 2013.

VUJOSEVICH, Jorge; GIMÉNEZ, Liliana; GODOY, Cecilia; MOREIRA, Stella. Travestis y VIH: cuando expandir las fronteras del sistema de salud pública constituye un desafío imediato. Archivos Hispanoamericanos de Sexologia, vol IX. 
